\title{
ESA's Soil Moisture and Ocean Salinity Mission: mission performance andoperations
}

\author{
Susanne Mecklenburg, Matthias Drusch, Yann Kerr, Jordi Font, \\ Manuel Martin-Neira, Steven Delwart, Guillermo Buenadicha, Nicolas Reul, Elena Daganzo-Eusebio, \\ Roger Oliva, RaffaeleCrapolicchio
}

Abstract - ESA's Soil Moisture and Ocean Salinity (SMOS) mission was launched on the $2^{\text {nd }}$ of November 2009. The first six months after launch, the so called commissioning phase, were dedicated to test the functionalities of the spacecraft, the instrument and the ground segment including the data processors. This phase was successfully completed in May 2010 and SMOS hassince beenin the routine operations phase and providing data products to the science community for overa year. The performance of the instrument has been within specifications. A parallel processing chain has been providing brightness temperatures in near-real time (NRT) to operational centres, e.g. the European Centre for Medium-Range Weather Forecasts (ECMWF). Data quality has been within specifications; however, radio frequency interference has been detected over large parts of Europe,China, Southern Asia and the Middle East. Detecting and flagging contaminated observations remains a challenge as well as contacting national authorities to localize and eliminate radio-frequency interference (RFI)sources emitting in the protected band. The generation of Level 2 soil moisture and ocean salinity data is an ongoing activity with continuously improved processors. This article will summarise the mission status after one year of operations and present selected first results.

Index TermsSoil Moisture and Ocean Salinity (SMOS) Mission, sea surface salinity, soil moisture, L-Band radiometry, satellite remote sensing. 
HERE TO EDIT) <

Manuscript received in April, 2011.

S.Mecklenburg, S.Delwart and R.Crapolicchio are with the European Space Agency, ESA-ESRIN, Via Galileo Galilei, Casella Postale 64, 00044 Frascati, Italy (e-mail: Susanne.mecklenburg @ esa.int )

M. Drusch, M.Martin-Neira and E.Daganzo-Eusebioare with the European Space Agency, ESAESTEC, Keplerlaan 1, 2200 AG Noordwijk, The Netherlands.

G.Buenadicha and R.Oliva are withtheEuropeanSpace Agency, ESA-ESAC, E-28691 Villanueva de la Cañada, Madrid, Spain.

Y. Kerr is with CESBIO (CNES/CNRS/UPS/IRD), 18, avenue EdouardBelin, 31401 Toulouse Cedex 9, France.

J.Font is with the Institut de Ciències del Mar, ICM-CSIC, and the SMOS Barcelona Expert Centre, P. Marítim de la Barceloneta 37-49, 08003 Barcelona, Spain.

N.Reul is with the Laboratoired'OcéanographieSpatiale, Ifremer, Plouzané, France.

\section{INTRODUCTION}

The Soil Moisture and Ocean Salinity (SMOS) mission, launched on 2 November 2009 from the PlesetskCosmodrome (Russia), is the European Space Agency's (ESA) second Earth Explorer Opportunity mission within its Living Planet Programme. The SMOS mission objectives are [1]: (1) To provide global volumetric soil moistureestimates with anaccuracy of $0.04 \mathrm{~m}^{3} \mathrm{~m}^{-3}$ at a spatial resolution of 35-50 km and a temporal sampling of 1-3 days and (2) To provide global ocean salinityestimates with anaccuracy of 0.1 practical salinity scale unitsfor a 10-30 day average for an open ocean area of $200 \times 200 \mathrm{~km}^{2}$.

These objectives directly respond to the scientific challenges outlined in ESA's scientific strategy for the Living Planet Programme, "The Changing Earth" [2], and address the need for high-quality global observations of soil moisture and ocean salinity from space. Both parameters are two key variables describing the Earth's water cycle and have been identified as Essential Climate Variables (ECVs) by the Global Climate Observing System (GCOS) [3]. Uncertainties in the description of the spatial and temporal dynamics in both parameters limit the predictive skill of hydrological, oceanographic and 
REPLACE THIS LINE WITH YOUR PAPER IDENTIFICATION NUMBER (DOUBLE-CLICK HERE TO EDIT) <

atmospheric models(e.g. [4]). SMOS observations are also expected to provide valuable information on the characterisation of sea ice and snow covered surfaces and enhance our understanding of the exchange processes between the surface and the atmosphere. A general overview on the SMOS mission can be found in $[5,32,33]$.

The payload of SMOS consists of the Microwave Imaging Radiometer using Aperture Synthesis (MIRAS) instrument, a passive microwave 2-D interferometric radiometer [6], operating in L-band $(1.413 \mathrm{GHz}, 21 \mathrm{~cm})$ within the protected $1400-1427 \mathrm{MHz}$ band. MIRAS comprises a central structure and three deployable arms holding the equally distributed 69 antenna elements. SMOS measures the brightness temperature emitted from the Earth at L-band over a range of incidence angles ( 0 to $\left.55^{\circ}\right)$ across a swath of approximately $1000 \mathrm{~km}$ with a spatial resolution of 35 to $50 \mathrm{~km}$. MIRAS has the functionality to provide measurements in dual and full polarisation, with the latter being the mode in which MIRAS is presently operated [7,34]. For a detailed description of the MIRAS components see [6].

The choice of L-Band as the spectral range in which to operate was determined by the high sensitivity to changes of moisture in the soil (e.g. [44]) and salinity in the ocean (e.g. [45]) largest for low microwave frequencies. Furthermore, observations at L-Band are less susceptible to attenuation due to the atmosphere or the vegetation than measurements at higher frequencies [8]. It also enables a larger penetration depth into the surface soil layer than at shorter wavelengths (e.g. [46]).

The nominal life of SMOS is expected to be 3 years, with a potential for extension depending on the technical status of the mission. The SMOS mission is based on a sun-synchronous orbit (dusk-dawn $6 a m / 6 \mathrm{pm})$ with a mean altitude of $758 \mathrm{~km}$ and an inclination of $98.44^{\circ}$. SMOS has 149 -day repeat cycle with a 3-day sub-cycle. The SMOS instrument MIRAS has been built by a consortium of over 20 
REPLACE THIS LINE WITH YOUR PAPER IDENTIFICATION NUMBER (DOUBLE-CLICK

HERE TO EDIT) <

European companies led by EADS-CASA Espacio, Spain (Figure 1) and is mounted on a generic PROTEUS platform developed by the French space agency CNES and Alcatel (France).

This article will first outline the mission operations concept and then address operational activities performed during the first year in orbit. This includes the commissioning phase, mission performance, and the detection and mitigation of RFI. We will then address the quality of the SMOS products showing results produced by ESA's SMOS Validation and Retrieval Team (SVRT). Details on the instrument calibration can be found in [9].

\section{THE OPERATIONS CONCEPT}

SMOS is an ESA Earth Explorer mission, which was developed in collaboration with the French Space Agency, the Centre National d'EtudesSpatiales (CNES), and the Spanish Centro para el DesarrolloTecnológicoIndustrial (CDTI). This collaborative approach continues in the operations phase: ESA isresponsible for the overall mission operations, instrument and ground segment operations whereas CNES isresponsible for the operations of the satellite.

Figure 2 shows the main stations of the ground segment to keep SMOS running day-to-day. The Data Processing Ground Segment (DPGS) is located at ESA-ESAC Villafrancadel Castillo (Spain), including the receiving station for the X-Band downlink of the science data, the data (re)processing and distribution facilities as well as facilities to check on the performance of the overall system as well as the product quality. ESAC also hosts the Flight Operations Segment (FOS) for instrument operations and instrument mission planning. The Satellite Operations Ground Segment (SOGS) at CNES in Toulouse performs all spacecraft operations. The Long-Term Archive at Kiruna (Sweden) holds the mission data archive and facilitates the dissemination of SMOS data. The User Services, based at ESA- 
REPLACE THIS LINE WITH YOUR PAPER IDENTIFICATION NUMBER (DOUBLE-CLICK HERE TO EDIT) <

ESRIN (Italy), take care of the interaction with the users in case of problems in the data handling. The ESA Post Launch Support Office, responsible for preventive and corrective maintenance of payload performances andleading on the procedures to follow in case of anomalies, is located at ESA-ESTEC (Netherlands).

SMOS also has the capability to provide data in near-real-time (NRT). Global observations of SMOS brightness temperatures and soil moisture are an important input for operational meteorological applications. Hence the acquisition and data processing facilities had to be compatible to the NRT delivery requirement this imposes. To guarantee the delivery of SMOS data to operational entities such as the European Centre for Medium-Range Weather Forecasting (ECMWF) within three hours from sensing, a further X-Band downlink station at Svalbard (Norway) was added to the mission operations concept. ECMWF is already monitoring the SMOS brightness temperatures globally in NRT and working on integrating SMOS data in their predictive models, thus testing the improvements SMOS data will be able to make to meteorological forecasts.

To ensure the continuous high quality and evolution of SMOS data products an advisory body called the SMOS Quality Working Group has been set up. This group considers the input from SMOS data users and advises on the implementation within the ESA operations set-up. A major source of feedback from the SMOS science community is provided by the so-called Expert Support Laboratories (ESLs), providing advice on calibration of the MIRAS data, the development of the retrieval algorithms to derive SMOS level 1 and 2 data products (Table 1), and the continuous quality control and evolution of SMOS data products.

\section{III.SMOS IN ORBIT}

Following the successful launch in November 2009, the first six months of SMOS in orbit were dedicated to test the functionalities of the spacecraft and instrument, the so called commissioning 
REPLACE THIS LINE WITH YOUR PAPER IDENTIFICATION NUMBER (DOUBLE-CLICK HERE TO EDIT) <

phase. This phase was successfully completed in May 2010 and SMOS has since been in the routine operations phase and providing data products (Figure 3) to the science community for over a year.

\section{A. Instrument performance and calibration}

The major outcome of the commissioning phase was to define the calibration strategy and assess the performance of SMOS in orbit. The majority of the instrument calibration tests took place during the Payload Commissioning (Figure 4). In the pseudo-operational phase the acquisition mode was alternated between dual and full polarisation mode on a weekly basis. It also comprised weekly external calibration manoeuvres and electrical stability tests[47] (Figure 4).

Table 3 summarises the main instrument performance parameters. All parameters are within specification except for the systematic error over ocean, which, depending on the surface roughness model used, ranges between 2.1 and $2.8 \mathrm{~K}$ for a specified value of $2.5 \mathrm{~K}$, and the long term stability, which is of about $0.25 \mathrm{~K} /$ year over ocean for a goal of $0.18 \mathrm{~K} /$ year. The systematic error over ocean was identified as the dominant error component during the commissioning phase and specific image reconstruction techniques were applied to remove it $[13,14]$. Further details on the MIRAS instrument performance can be found in [13].

The activities performed in the commissioning phase allowed us to define the optimal rate for the different calibration activities required to remove instrumental errors (Table 2). The Flat Target Response (FTR) of the system showed highly stable antenna patterns for long periods of time with variations that accounted for less than $0.2 \mathrm{~K}$ after 6 months of data, leading to the decision to perform one FTR acquisition every 6 months. The instrument electronics also proved to be very stable with variations below $0.043 \%$ per week, thus requiring internal calibration only every 8 weeks. The Noise Injection Radiometers (NIR) were noticed to drift towards the end of the commissioning phase and a 


\section{REPLACE THIS LINE WITH YOUR PAPER IDENTIFICATION NUMBER (DOUBLE-CLICK HERE TO EDIT) <}

cold sky calibration rate of 2 weeks was deemed necessary to stay within the short-term stability specification [37]. Finally, much effort was dedicated to establish the best calibration rate to correct the varying phase difference across local oscillators in MIRAS, negotiating between data quality and quantitative availability of data, which was set to 10 minutes with a commitment to review this decision later in the mission.

The calibration strategy established by the end of the commissioning phase has been consolidated with data accumulated during the operational phase, leading to an additional short calibration activity once a week, since small variations accounting for $0.5 \%$ per week have been observed in the detector offsets.

A major decision of the commissioning phase review was to operate MIRAS in full polarisation mode, which was based on (a) the fact that no L-band polarimetric mission has been flown to date, hence providing an entirely new type of observations to the users, (b) the potential to improve level 2 ocean salinity data products, and (c) the usefulness of Stokes-3 and - 4 parameters to detect and flag radiofrequency interference (RFI) from man-made emissions, one of the major sources to decrease the SMOS data quality at present. In addition, the full polarimetric mode does not have a negative impact on system performance such as power, temperature, down-link scenario, mass memory managementetc, only a degradation of about $30 \%$ on radiometric noise due to the lower sampling rate for each polarisation.

\section{B. Mission status}

The space segment - payload and platform - is generating observation data within the system performance requirement of 98\%. For example, for April to December 2010 anomalies caused a total of on-board data loss of $0.25 \%$ and degraded data of $0.38 \%$. The anomalies are suspected to be mainly driven by radiation effects. They affect several units like the Control and Monitoring Nodes (CMN), 


\section{REPLACE THIS LINE WITH YOUR PAPER IDENTIFICATION NUMBER (DOUBLE-CLICK}

HERE TO EDIT) <

the Mass Memory - the on-board memory, and the Control and Correlation Unit (CCU) [6]. Each CMN is associated withan arm segment and the hub and handles the commands from and the telemetry to the central computer, the CCU.

The ground segment is acquiring, processing and delivering data to users up to level 2 and providing data in NRT to operational agencies, such as ECMWF. All science data have been acquired without data gaps. Level 1 and 2 data products are available to the science community since July and October 2010, respectively. The data production for April to December 2010 was successfully completed for $96 \%$ of all level 1 data available, for level 2 soil moisture and ocean salinity data for $95 \%$ and for NRT data for $97 \%$. The NRT data product is delivered to ECMWF within 3 hours from sensing for $87 \%$ of all data available. Level 1 and 2 data products are available to users within 1-3 days after sensing. The first complete reprocessing of SMOS data products up to level 2 is foreseen for the end of 2011.

\section{PRODUCT ANALYIS AND VERIFICATION}

In this section we will address validation activities, the level 1 (brightness temperature) data quality, the level 2 soil moisture and ocean salinity processor verification and the development of higher level data products. We will also summarise the status on radio frequency inference (RFI).

\section{A. Validation activities and Level 1 data quality}

Major undertakings in any environmental science related satellite mission are the validation activities. An important part of the validation activities for SMOS is facilitated through ESA's close collaboration with key scientific groups, the above mentioned Expert Support Laboratories (ESL) [19]. In addition, 
REPLACE THIS LINE WITH YOUR PAPER IDENTIFICATION NUMBER (DOUBLE-CLICK HERE TO EDIT) <

SMOS validation activities largely rely on national contributions from ESA member states. ESA essentially provides SMOS data to a selected group of scientists already before the official release of data in exchange for results from their investigations. This guarantees a large number of validation activities being covered, combining a variety of climate and vegetation areas and observations from airborne and in-situ measurements. Feedback is gathered through so called validation workshops and serves as input for data product quality improvements through the work of the ESLs.

There are also direct investments from ESA's side into instrumentation and airborne campaigns. For example, the validation of the level $1 \mathrm{C}$ brightness temperature data product was primarily done on the Antarctic Plateau, where France and Italy operate the DOME-C Concordia Research Station. The observation region is rather homogeneous and provides a relatively stable target, providing optimum conditions for stability monitoring, as shown by [20]. ESA funded the operations of a ground-based LBand radiometer, RADOMEX, developed by IFAC-CNR, Florence (Italy) [20].

A further source for better understanding in particular the SMOS NRT brightness temperaturedata, an equivalent to the level 1C data product but in BUFR format, is provided by ECMWF. Data monitoring, i.e. the comparison between model-based brightness temperatures and observations, has been performed routinely and has provided a valuable monitoring tool to check on SMOS data quality. In the near future SMOS data will be used in the land surface analysis scheme [21] to assess their impact on the forecast quality [38].

The collaboration with NASA's Aquarius and SMAP teams also provide valuable input for validation activities and thus improving SMOS data products. ESA and NASA are presently discussing the collaboration between these three missions in particular with regard to combining efforts for the calibration \& validation activities and the RFI detection and mitigation. There is also interest to find a 
REPLACE THIS LINE WITH YOUR PAPER IDENTIFICATION NUMBER (DOUBLE-CLICK

HERE TO EDIT) <

common approach for the continuity of soil moisture and ocean salinity observations in future, in the context of soil moisture and ocean salinity being Essential Climate Variables [3].

\section{B. Radio Frequency Interference}

RFI disturbs the natural microwave emission in the L-band frequency making the satellite observations in some casesuseless for retrieving SMOS data products under these conditions[18]. RFI originates from man-made emitters on the ground, on aircraft or space borne systems. These emitters add signal to the natural radiation emitted by the Earth which is very low when compared to the emission from active sources. Therefore, most passive sensors in the Earth Exploration Satellite Service (EESS) operate within purely passive frequency bands where emissions from active servicesare prohibited by ITU-R Radio Regulations (RR 5.340) [15]. However, these bands can be contaminated by unauthorised systems operating within the passive bands and by unwanted emissions from active service stations operating in neighbouring frequency bands. RFI is not a SMOS specific problem occurring only at Lband but has been detected with other sensors as well [16]. However, at L-band the area affected by interference sources is larger than at higher frequencies. While the solution of the RFI due to illegal transmission can be achieved through cooperation with the national authorities reinforcing the ITU regulations, the solution of the excessive unwanted emissions problem requires further regulatory action. The latest World Radio Conference (WRC) in 2007 adopted recommended levels of out-ofband emissions falling within this passive band (ITU RR Resolution 750). In Europe, the Conference of European Post and Telecommunications (CEPT) administrations have recently adopted a decision to make these levels compulsory within their territories in order to have an adequate and long-term protection of this essential passive band in the frequency range 1,400-1,427 MHz. 


\section{REPLACE THIS LINE WITH YOUR PAPER IDENTIFICATION NUMBER (DOUBLE-CLICK HERE TO EDIT) <}

Constant monitoring of the retrieved data is needed in order to take adequate actionsfor the mitigation and removal of RFI sources. A number of techniques for the detection of RFI have been identified. They can be classified in three categories [17]: temporal, spectral, and statistical - some techniques are a combination of two or more. Reference[18] provides a comprehensive overview on the RFI situation in SMOS. The results presented in Figure 5 are probabilities of RFI occurrence based on a simple threshold algorithm where brightness temperatures exceeding $340 \mathrm{~K}$ were masked as RFI. This threshold is very conservative and necessarily considers a non-thermal noise emission, even though some low level RFI sources mightpass undetected. The same threshold is currently being applied for the flagging in the operational level $1 \mathrm{C}$ data product.

Figure 5a clearly shows that the impact of RFI is variable in space and time and that a single RFI source in Spain can contaminate large parts of North-western Africa. The RFI problem is stronger over landbut has also been detected over ocean, in particular in the Northern hemisphere above 55 degree latitude due to RFI sources in North America and Russia. Currently, large parts of Southern Europe, China, Southern Asia (e.g. the Bay of Bengal) and the Middle East (e.g. the Arabian Sea) are strongly affected by RFI.

ESA's and the scientists' actions to reduce the impact of RFI in SMOS data products have significantly improved the overall situation, as can be seen in Figure $5 \mathrm{~b}$ in particular. SMOS scientists have been investigating different methods for the RFI detection in close collaboration with the Expert Support Laboratories [27]. Future versions of the Level 1 and Level 2 data will result in an improved RFI flagging and monitoring. In parallel, ESA has been in contact with the National Frequency Management Authorities of those countries with RFI sources over their territory, and investigations and on-site measurements have allowed the elimination of many RFI sources. The significant improvement of the RFI scenario over Europe can be noted from Figure 6, where ESA member states are making 


\section{REPLACE THIS LINE WITH YOUR PAPER IDENTIFICATION NUMBER (DOUBLE-CLICK HERE TO EDIT) <}

great efforts to reduce the number of RFI sources that are contaminating SMOS observations. As of July2011, 98interferers were successfully located and switched-off over Europe.

\section{Selected results from the Level 2 verification}

The step from multi-angular brightness temperatures at the top of the atmosphere (level 1c) to level 2 soil moisture and sea surface salinity products is rather complex and involves radiative transfer computations over heterogeneous surfaces. The accuracy of the level 1c data depends on a number of instrument parameters (radiometric sensitivity and accuracy, calibration stability, etc.) and the interferometric image reconstruction. Uncertainties in the level 2 products are further introduced through the auxiliary data sets, simplified modeling of L-band emission and a spatial scale of $50 \mathrm{~km}$ that does not account for the small-scale heterogeneities of the relevant geophysical parameters. Another common challenge for applications is that SMOS observations provide information on the very top layer of the ocean and the land surface only.

This special issue contains a number of detailed articles on the soil moisture and ocean salinity data product generation and verification $[35,49,50,51,24,52,53,54,58]$. In this general overview article, we will briefly address the fundamentals of the level 2 algorithms and give two examples, which are showing the state-of-the-art of the validation efforts and the challenges.

\section{1) Soil Moisture}

Over land, the observed polarized brightness temperatures $\mathrm{T}_{\mathrm{b}}$ at the top of the atmosphere (TOA) depend on atmospheric parameters, the soil surface and the canopy layer. The so-called $\tau$ - $\omega$ model (e.g [8]) forms the basis of the level 2 soil moisture algorithm:

$T_{b}=T_{b, a u}+\exp \left(-\tau_{a u}\right)\left(T_{b, a d}+T_{b, s k y} \exp \left(-\tau_{a d}\right)\right) \exp \left(-2 \tau_{c}\right) r+\exp \left(-\tau_{a u}\right)\left((1-r) T_{e} \exp \left(-\tau_{c}\right)+T_{c}(1-\omega)\left(1-\exp \left(-\tau_{c}\right)\right)\left(1+r \exp \left(-\tau_{c}\right)\right)\right)$ with $\mathrm{T}_{\mathrm{b} \text {,au }}$ and $\mathrm{T}_{\mathrm{b} \text {,ad }}$ the upward and downward atmospheric radiation, respectively, $\tau_{\mathrm{au}}$ and $\tau_{\mathrm{ad}}$ the 
REPLACE THIS LINE WITH YOUR PAPER IDENTIFICATION NUMBER (DOUBLE-CLICK HERE TO EDIT) <

upward and downward path atmospheric opacities, $T_{b, s k y}$ the cosmic background radiation, $\tau_{c}$ the canopy opacity, $r$ the surface reflectivity, $T_{e}$ the surface temperature, $T_{c}$ the canopy temperature and $\omega$ the vegetation single scattering albedo. This approximates the solution of the vector radiative transfer equation and neglects reflections at the air-vegetation interface and multiple scattering in the vegetation layer.The key geophysical parameters influencing the reflectivity are surface soil moisture, temperature and roughness. The canopy opacity depends on temperature, water contentand structure.It is assumed that the TOA brightness temperature is composed from bare soil and vegetation covered soil. From previous field experiments it was found that changes of $0.2 \mathrm{~m}^{3} \mathrm{~m}^{-3}$ volumetric soil moisture cause brightness temperature variations of 40 - $60 \mathrm{~K}$ depending on vegetation type and coverage [40].

The level 2 retrieval algorithm uses the $\tau$ - $\omega$ model for forward calculations and minimizes a cost function for soil moisture and vegetation opacity. A number of auxiliary data sets, e.g. Moderate Resolution Imaging Spectrometer (MODIS) derived leaf area index (LAI), ECOCLIMAP land cover classification, Food and Agricultural Organization (FAO) soil types, ECMWF temperature forecasts, are used as input parameters. In addition, auxiliary data sets are used to mask areas where no soil moisture retrievals can be obtained, e.g. under the presence of snow. The spatial heterogeneity and the non-linear antenna gain function are explicitly taken into account for the forward calculations. For more details on the level 2 processor the reader is referred to [42].

For the validation of the soil moisture data products ESA's activities focus on key validation sites in Germany, Spain, and Finland. These sites also form part of the airborne campaigns [55] organised and funded by ESA, in collaboration with CNES. ESA's support to these sites also includes the deployment of three ground-based L-Band ELBARA radiometers [28, 36, 48, 49]. ESA also supports the establishment of the International Soil Moisture Network Data Base, providing central access to in-situ soil moisture data provided by various suppliers worldwide (http://www.ipf.tuwien.ac.at/insitu/). Level 2 soil moisture data products are currently being compared against predicted soil moisture fields from 
REPLACE THIS LINE WITH YOUR PAPER IDENTIFICATION NUMBER (DOUBLE-CLICK

HERE TO EDIT) <

ECMWF's Integrated Forecasting System [22], in-situ observations taken during the calibration and validation activities outlined above or against measurements from operational soil moisture networks $[23,24]$.

The Soil Climate Analysis Network (SCAN) is an automated network of stations in the United States providing soil moisture measurements in NRT. It is administered by the United States Department of Agriculture Natural Resources Conservation Service (NRCS) through the National Water and Climate Center (NWCC). The network has more than 116 stations located in 39 states [31] and has been included in the International Soil Moisture network data base. Data from selected stations have been used for comparisons against observations from the closest SMOS grid point and the corresponding ECMWF model grid point. As an example, results for site 2059 (Newby Farm, Alabama, 34 51' N, $\left.86^{\circ} 53^{\prime} \mathrm{W}\right)$ are shown and discussed in Figure 7.

The first point to note is the different soil moisture climatology of the model data set. Soil moisture values from ECMWF are generally higher than the in-situ measurements and the dynamic range in the data is smaller by comparison. This is consistent with earlier results [25] and stems from the fact that modelled soil moisture values depend on the values selected for the permanent wilting point and saturation. In addition, the soil moisture data sets represent different sampling depth: while the model data have been computed for a $7 \mathrm{~cm}$ layer, the satellite derived data describe a weighted average over the top few centimetres. The magnitude of the dry down occurring during the summer months is underestimated. This is also in line with previous results [22]. However, the effects of the main rain events are well captured in the modelled time series.

The bias between the two data sets is comparatively small $\left(0.02 \mathrm{~m}^{3} \mathrm{~m}^{-3}\right)$ with SMOS showing lower values than the in-situ measurements. This systematic difference is largest in spring time when the insitu measurements show consistently high values between 0.3 and $0.4 \mathrm{~m}^{3} \mathrm{~m}^{-3}$ whereas the SMOS 


\section{REPLACE THIS LINE WITH YOUR PAPER IDENTIFICATION NUMBER (DOUBLE-CLICK HERE TO EDIT) <}

observations range from 0.2 to $0.4 \mathrm{~m}^{3} \mathrm{~m}^{-3}$. The correlation between both data sets is 0.8 and the rms error is $0.078 \mathrm{~m}^{3} \mathrm{~m}^{-3}$. For 106 stations of the SCAN network correlations between 0.1 and 0.9 were found with a mean value of 0.51 for the 2010 period [57]. A more detailed analysis of the rms errors as a function of the SCAN site characteristics is given in [58], with lower rms errors over low vegetation sites typically in the range of 0.03 to $0.06 \mathrm{~m}^{3} \mathrm{~m}^{-3}$. Given the error in the in-situ measurements and the uncertainty that is introduced by the different spatial scales represented through the observations, these values are well within expectations. The time series of vegetation optical depth shows very little variation with the highest values in summer. Unfortunately, there are no corresponding ground-based data for an independent validation. Vegetation optical depth can, however, be compared against the different vegetation indices, e.g. Leaf Area Index, Normalized Difference Vegetation Index, Enhanced Vegetation Index or Normalized Difference Water Index, from the Moderate Resolution Imaging Spectrometer (MODIS) or other optical instruments.

\section{2) Ocean Salinity}

Over oceans, the emitted brightness temperature $T_{b \text {,sea }}$ can be modeled through a flat sea component and the contributions from the rough ocean $\left(\mathrm{T}_{\mathrm{b}, \text { rough }}\right)$ and foam $\left(\mathrm{T}_{\mathrm{b}, \text { foam }}\right)$ [e.g. 56]:

$T_{b, \text { sea }}=\left(T_{b, \text { flat }}+T_{b, \text { rough }}\right)(1-F)+T_{b, \text { foam }}$

where $\mathrm{F}$ is the fraction of sea foam coverage. When atmosphere and the extraterrestrial source are considered we obtain for the brightness temperature at the bottom of the atmosphere $\left(\mathrm{T}_{\mathrm{b}, \mathrm{BOA}}\right)$ :

$$
T_{b, B O A}=T_{b, s e a}+\left(T_{b, a d} \Gamma+T_{g a l_{-} r e f l} \exp \left(-\tau_{a d}\right)\right)
$$

with the $\Gamma$, the reflectivity of the ocean surface at L-band and $T_{\text {gal_refl, }}$ the contribution from extraterrestrial radiations scattered by the ocean surface upward. The sources for these radiations are the hydrogen line, the uniform cosmic microwave background and the continuum at $\sim 1.4 \mathrm{GHz}$. The TOA brightness temperatures are computed using:

$T_{b}=T_{b, B O A} \exp \left(-\tau_{a u}\right)+T_{b, a u}$ 


\section{REPLACE THIS LINE WITH YOUR PAPER IDENTIFICATION NUMBER (DOUBLE-CLICK HERE TO EDIT) <}

The main geophysical parameters influencing $T_{b \text {,sea }}$ are sea surface salinity, temperature and the sea surface state.The absolute sensitivity of the brightness temperatureto sea surface salinity changes is low and depends on temperature: $0.2 \mathrm{~K}\left(\right.$ at $\left.0^{\circ} \mathrm{C}\right)$ to $0.8 \mathrm{~K}\left(30^{\circ} \mathrm{C}\right)$ per practical salinity unit. As a consequence it is more demanding to retrieve sea surface salinity at higher latitudes (i.e. in colder waters). Furthermore, the low radiometric sensitivitylimits the accuracy for salinity estimates from a single pass, which makes temporal and spatial averaging necessary.

The iterative Levenberg and Marquard method is chosen for the inversion algorithm minimizing a cost function. Details on the ocean salinity retrieval can be found in [43]. The ocean's surface roughness contribution to emissivity is estimated from auxilliary surface wind speed information obtained from ECMWFthrough three different formulations of $\mathrm{T}_{\mathrm{b}, \text { rough }}$ based on theoretical and empirical approaches proposed before launch and now being tuned to SMOS measurements. Global sea surface temperature data are also obtained from ECMWF's analysis, which is based on the Operational Sea Surface Temperature and Sea Ice Analysis (OSTIA) system [41].

To assess the quality of the Level 2 and Level 3 SMOS sea surface salinity (SSS) data, a comparison with in-situ data acquired in the upper 10 meters of the ocean from ARGO float observations, the Tropical Atmosphere Ocean mooring arrayas well as with observations from thermosalinographsonboard ships of opportunity, has been carried out. The majority of in-situ observations are from the ARGO network which is an international programme using autonomous floats to collect temperature, salinity and deep current data. The target of ARGO, reached in 2007, is to deliver data from 3000 floats within 24 hours to operational users and operational centres. 23 countries provide individual floats to meet these objectives. Details on the programme can be found in [30].

Global satellite and in-situ sea surface salinity co-localized data sets have been produced using the SMOS L1 (B and C) observations and the in-situ database for the period from July to December 2010 


\section{REPLACE THIS LINE WITH YOUR PAPER IDENTIFICATION NUMBER (DOUBLE-CLICK HERE TO EDIT) <}

(Fig. 8). The results presented in Fig. 8 combine measurements from ascending and descending orbits without anin-depthquality check of the individual values. However, it can be noted that the main global features are well represented in the satellite derived data set.

Over the second half of 2010 [35], 95\% of the SMOS Level 2 products are found to exhibit a global mean error $\Delta \mathrm{SSS}=\mathrm{SSS}_{\mathrm{SMOS}}-\mathrm{SSS}_{\text {in situ }}$ of 0.52 with a standard deviation of 1.3. In the tropical oceans, the mean error decreases to about 0.3 with a standard deviation of 1 . The standard deviation of the error is found to be systematically less for ascending orbits ( 1.1 globally and 0.8 in the tropics) than for the descending ones (1.4 globally and 1.1 in the tropics). A more detailed comparison using $1^{\circ} \times 1^{\circ}$ spatial averages combining measurements from ascending and descending orbits reveals a bias of 0.16 with SMOS showing systematically lower values than the corresponding in-situ data. Only for values below 32 the SMOS-based estimates are higher than the in-situ observations (Fig. 8). The distribution of the differences between the in-situ data and the SMOS Level 3 estimates are almost Gaussian distributed with a standard deviation of $\sim 0.4$. If the median error described as one standard deviation is calculated for 0.5 bins it is confirmed that SMOS performs better for salinity values exceeding 33 with the highest accuracies at values above 36 (Fig. 8). These increased errors at low salinities are dominated by the impact of strong RFI in the fresh waters of the Northern latitudes and of the Bay of Bengal. In the Tropical oceans, the SMOS Level 3 SSS standard deviation error is in the order of 0.38, except during the period from October to November for the descending passes, for which it reaches an higher 0.5-0.6 error, potentially associated with the signal contamination by direct sun radiations. Note as well that, due to an image reconstruction artefact whichhas been corrected after the 2011 reprocessing, a systematic bias in the retrieved SSS was also found along the world coasts, occurring in presence of the strong brightness temperature gradients associated with the sea/land transitions. 


\section{REPLACE THIS LINE WITH YOUR PAPER IDENTIFICATION NUMBER (DOUBLE-CLICK HERE TO EDIT) <}

Accuracyinthe order of 0.4 for a temporal average of 1 month at $1^{\circ} \times 1^{\circ}$ spatial resolution is still far away from the mission objectives outlined in Section 1. However, given the limitations and caveats outlined above these preliminary results are very encouraging.

It has to be noted that the full range of brightness temperature corresponding to all the salinity values in the world oceans is some twenty times smaller than the range for all possible soil moisture values. This implies that the salinity retrieval by SMOS requires a moreprecise calibration of the instrument and better image reconstruction. When improved L1C data will be available the validation of ocean salinity will be done using dedicated measurements close to the surface by drifting buoys, in addition to the bulk salinity values provided by ARGO.

\section{Higher level data products}

In parallel to these operational activities, ESA has been initializing and supporting a number of activities related to data exploitation and the generation of new Level 2 or Level 3 products. These projects have been partly funded through ESA's Support to Science Element framework. At ECMWF, the NRT brightness temperatures are being monitored and assimilated through the Kalman filter based surface analysis system, which became operational in November 2010 [21]. Using the SMOS data and $2 \mathrm{~m}$ temperature and humidity analyses the top-most soil layers representing $1 \mathrm{~m}$ depth will be updated. Based on these analysed model fields a SMOS based root zone soil moisture product will be generated on a routine basis. Another exploratory activity addresses the derivation of vegetation water content using the operational vegetation opacity product and auxiliary information from numerical soilvegetation-atmosphere transfer models.

Results from the ELBARA calibration / validation site [28, 36] indicated that SMOS observations can also be used to detect frozen soils and derive a thaw / freeze classification. It was shown that the brightness temperature remains temporally very stable over frozen soils, even under the presence of 


\section{REPLACE THIS LINE WITH YOUR PAPER IDENTIFICATION NUMBER (DOUBLE-CLICK HERE TO EDIT) <}

thick snow layers. Variations in brightness temperatures prior to soil freezing are mainly caused by soil moisture and temperature variations. During spring time the melting and re-freezing of the snow layer introduces brightness temperature variations on the daily time scale before soil moisture variations can be detected for the unfrozen soil.

Another future SMOS Level 3 product under development is sea ice thickness. Following a preparatory study on L-band emissivity of sea ice [29] and a comparison between L-band derived thickness and electromagnetic induction measurements during the 2007 Pol-Ice campaign an Algorithm Theoretical Baseline Document is being prepared to facilitate the operational processor. Initial results produced for the Arctic winter in 2010 and 2011 are currently being evaluated.

\section{SUMMARY AND OUTLOOK}

SMOS has been in its operational phase since May 2010. The instrument performance, the volume of science data provided, and the timeliness of data delivery have been within specifications. RFI has been found to be one of the major sources of uncertainty and a limiting factor for applications in certain parts of the world. In general, contamination over land is higher than over the ocean surfaces. However, large parts of the Northern Atlantic are affected by RFI as well. ESA and the science community have been addressing this problem effectively, so that the total number of RFI sources has been reduced and the RFI detection methods have been constantly improved.

The processors generating brightness temperatures and level 2 soil moisture and ocean salinity data products have been continuously improved. However, the mission's scientific objectives, namely to provide global volumetric soil moistureestimates with anaccuracy of $0.04 \mathrm{~m}^{3} \mathrm{~m}^{-3}$ at a spatial resolution of 35-50 km and a temporal sampling of 1-3 days and (2) to provide global ocean salinityestimates with anaccuracy of 0.1 practical salinity scale units for a 10-30 day average for an open ocean area of $200 \mathrm{x}$ 
REPLACE THIS LINE WITH YOUR PAPER IDENTIFICATION NUMBER (DOUBLE-CLICK

HERE TO EDIT) <

$200 \mathrm{~km}^{2}$, have not been reached yet. Main areas for improvement for the soil moisture retrieval are related to RFI detection and mitigation, a new parameterization for the soil dielectric constant following [26] andimproved auxiliary data sets for snow coverage and soil types.For the ocean salinity retrieval similarly a main area for improvement remains RFI, in particular in the higher latitudes of the Northern Hemisphere,as well as improved models for the correction of sea surface roughness effectsand the impact of external sources radiation (Sun, galaxy).

ESA has also been supporting a number of activities related to the generation of new Level 2 or Level 3 products, for example the development of a SMOS based root zone soil moisture product, algorithms to detect frozen soils and derive a thaw / freeze classification and a sea ice product. Efforts are also made at national level in France with the Centre AvalTraitement des Donnes (CATDS) and in Spain with the SMOS Level 3/4 Processing Centre (CP34) to deliver elaborated level 3 and 4 data products of interest to the international research community.

Since SMOS provides - for the first time ever - fully polarimetric observations at L-band from space, we expect a large number of innovative scientific results from this mission in the coming years. In addition, we envisage that operational agencies, e.g. weather and hydrological forecast centres, will benefit from this novel type of observations.

\section{ACKNOWLEDGEMENTS}

The authors would like to express their thanks to the various scientific and industrial teams involved in the development and operations of the SMOS mission for their valuable contributions. The work by ICM-CSIC was supported by the Spanish Ministry of Science and Innovation through grant AYA201022062-C05-01. The work by CESBIO and IFREMER was supported by the Centre National d'EtudesSpatiales (CNES) in the TOSCA Framework. 
REPLACE THIS LINE WITH YOUR PAPER IDENTIFICATION NUMBER (DOUBLE-CLICK HERE TO EDIT) < 


\section{REFERENCES}

[1] Mission Objectives and Scientific Requirements of the Soil Moisture and Ocean Salinity (SMOS) Mission (MRD), EEOM-SMOS-MRD, issue 5.

[2] The Changing Earth - New scientific challenges for ESA's Living Planet Programme, ESA Publication, SP-1304, July 2006.

[3] Systematic observation requirements for satellite-based products for climate, WMO/TD No. 1338, GCOS-107, September 2006.

[4] L. Ferranti and P. Viterbo:"The European summer of 2003: Sensitivity to soil water initial conditions", J. Climate, 19, 3659-3680, 2006

[5] Y.Kerr, P.Waldteufel, J.P.Wigneron, J. M. Martinuzzi, J. Font, and M. Berger, "Soil moisture retrieval from space: The Soil Moisture and Ocean Salinity (SMOS) mission,” IEEE Trans. Geosci. Remote Sens.,vol. 39, no.8, pp. 1729-1735, Aug. 2001.

[6] K. McMullan, M. Brown, M. Martin-Neira, W. Rits, S. Ekholm, J. Marti and J. Lemanczyk: “SMOS: The payload”, IEEE TGARS, 46, 594 - 605, 2008

[7] E. Anterrieu and A. Khazaal: "Brightness temperature map reconstruction from dual-polarimetric visibilities in synthetic aperture imaging radiometry”, IEEE TGARS, 46, 594 - 605, 2008 
REPLACE THIS LINE WITH YOUR PAPER IDENTIFICATION NUMBER (DOUBLE-CLICK HERE TO EDIT) <

[8] Y. Kerr and E. Njoku: "A semi-empirical model for interpreting microwave emission from semiarid land surfaces as seen from space", IEEE TGRS, 28, 384 - 393, 1990

[9] Brown M.A., Torres F., Corbella I., Colliander A.: "SMOS Calibration”, IEEE TGARS, 46, 646$658,2008$.

[10] Level 1 Product Specification, SO-TN-IDR-GS-0005 L1 Spec v5.16 2010-05-31

[11] Level 2 Product Specification, SO-TN-IDR-GS-0006 L2 Spec v5.2 2010-08-30

[12] NRT Product Specification, SO-ID-DMS-GS-0002 - NRT Product Format v3_0

[13] R. Oliva, M. Martin-Neira, I. Corbella, F. Torres, J. Kainulainen, J. Tenerelli, F. Cabot, F. MartinPorqueras: "SMOS Calibration and Performances after one year of data", this Special Issue, 2011

[14] J. Font, J. Boutin, N. Reul, P. Spurgeon, J. Ballabrera-Poy, A. Chuprin, C. Gabarró, J. Gourrion, C. Hénocq, S. Lavender, N. Martin, J. Martínez, M. McCulloch, I. Meirold-Mautner, C. Mugérin, F. Petitcolin, M. Portabella, R. Sabia, M. Talone, J. Tenerelli, A. Turiel, J.L. Vergely, P. Waldteufel, X. Yin, S. Zine, and S. Delwart, "SMOS first data analysis for sea surface salinity determination”, Int. J. Rem. Sens., accepted, 2011.

[15] Vol I (Articles) of the Radio Regulations, International Telecommunications Union, Edition of 2008 [available through the ict regulation toolkit under http://www.ictregulationtoolkit.org/en/PracticeNote.aspx?id=2824].

[16] E.G. Njoku, P. Ashcroft, T.K. Chan and L.Li, "Global survey and statistics of radio-frequency interference in AMSR-E land observations”, IEEE TGARS, 43, 5, 938 - 947, 2005. 
REPLACE THIS LINE WITH YOUR PAPER IDENTIFICATION NUMBER (DOUBLE-CLICK HERE TO EDIT) <

[17] J. R. Piepmeier and F. A. Pellerano, "Mitigation of terrestrial radar interference in L-band spaceborne microwave radiometers," in Proc. IGARSS, Denver, CO, Jul. 2006, pp. 2292-2296.

[18] R. Oliva, E. Daganzo, Y. Kerr, S. Mecklenburg, S. Nieto, P. Richaume, C. Gruhier: 'SMOS RF Interference Scenario: Status and Actions Taken to Improve the RFI Environment in the 1400-1427 MHz Passive Band', this Special Issue, 2011

[19] S.Delwart, C.Bouzinac, P.Wursteisen, M.Berger, M.Drinkwater, M.Martín-Neira, Y.Kerr, "SMOS Validation and COSMOS campaigns", IEEE Trans. Geosci. Remote Sens.,vol. 46, no. 3, pp. 695-704, March 2008.

[20] Macelloni G., M. Brogioni, S. Pettinato, R. Zasso, A. Crepaz, J. Zaccaria, B. Padovan, M. Drinkwater, "MULTI-FREQUENCY MICROWAVE EMISSION OF THE EAST ANTARCTIC PLATEAU", Geoscience and Remote Sensing Symposium, 2011 IEEE International, IGARSS 2011, 22-29 July 2011, in press

[21] M. Drusch, K. Scipal, P. de Rosnay, G. Balsamo, E. Andersson, P. Bougeault and P.Viterbo: Towards a Kalman Filter based soil moisture analysis system for the operational ECMWF Integrated Forecast System, Geophys. Res. Let., 36, p 1029, 2009.

[22] M. Drusch and P. Viterbo: “Assimilation of screen-level variables in ECMWF's Integrated Forecast System: A study on the impact on the forecast quality and analysed soil moisture", Mon. Wea. Rev., 135, $300-314,2007$ 
REPLACE THIS LINE WITH YOUR PAPER IDENTIFICATION NUMBER (DOUBLE-CLICK HERE TO EDIT) <

[23] W. Dorigo, W. Wagner, R. Hohensinn, S. Hahn, C. Paulik, M. Drusch, S. Mecklenburg, P. van Oevelen, A. Robock and T. Jackson: "The International Soil Moisture Network: A data hosting facility for global in situ soil moisture measurements", submitted to HESS, 2011

[24] T. J. Jackson, R. Bindlish, M. Cosh, T. Zhao, P. Starks, D. Bosch, M. Seyfried, S. Moran, D. Leroux and Y. Kerr, "Validation of Soil Moisture Ocean Salinity (SMOS) Soil Moisture over Watershed Networks in the U.S.”, Submitted to this special issue

[25] M. Drusch, E.F. Wood, and H. Gao: “Observation operators for the direct assimilation of TRMM Microwave Imager retrieved soil moisture”, Geophys. Res. Let., 32, L15403, doi:10.1029/2005, GL023623

[26] V.L. Mironov, M.C. Dobson, V.H. Kaupp, S.A. Komarov, V.N. Kleshchenko:"'Generalized refractive mixing dielectric model for moist soils”, IEEE TGRS, 42, 773 - 785, 2004

[27] Castro, R., Gutierrez, A. and Barbosa, J., "A first set of techniques to detect Radio Frequency Interferences and mitigate their impact on SMOS data”, this Special Issue, 2012.

[28] K. Rautiainen, J. Lemmetyinen, J. Vehvilainen, M. Drusch, A. Kontu, J. Kainulainen and J. Seppaenen: "L-Band Radiometer Observations of Soil Processes in Boreal and Sub-Arctic Environments", this Special Issue, 2011

[29 ] L. Kaleschke, N. Maass, C, Haas, S. Hendricks, G. Heygster and R.T. Tonboe: “A sea ice thickness retrieval model for $1.4 \mathrm{GHz}$ radiometry and application to airborne measurements over low salinity sea ice”, The Cryosphere Discuss., 3, 995 - 1022, 2009 
REPLACE THIS LINE WITH YOUR PAPER IDENTIFICATION NUMBER (DOUBLE-CLICK

HERE TO EDIT) <

[30] J. Gould, D. Roemmich, S. Wijffels, H. Freeland, M. Iganszewski, X. Jianping, S. Pouliquen, Y. Desaubies, U. Send, K. Radhakrishnan, K. Takeuchi, K. Kim, M. Danchenkov, P. Sutton, B. King, B. Owens, and S. Riser: "ARGO profiling floats bring new era of in situ ocean observations", EOS, 85 (19), 179, 190-191, 2004

[ 31 ] G.L. Schaefer, M.H. Cosh, T. Jackson, "The USDA natural resources conservation service soil climate analysis network (SCAN)”, J. Atmos. Oceanic Technol., 24, 2073 - 2077

[32] Y.H. Kerr, P. Waldteufel, J.P. Wigneron, S. Delwart, F. Cabot, J. Boutin, M.J. Escorihuela, J. Font, N. Reul, C. Gruhier, S. Juglea, M.R. Drinkwater, A. Hahne, M. Martín-Neira, and S. Mecklenburg, "The SMOS mission: New tool for monitoring key elements of the global water cycle", P. IEEE, vol. 98, pp. 666-687, 2010.

[33] J. Font, A. Camps, A. Borges, M. Martín-Neira, J. Boutin, N. Reul, Y.H. Kerr, A. Hahne, and S. Mecklenburg, "SMOS: The challenging sea surface salinity measurement from space", P. IEEE, vol. 98, pp. 649-665, 2010.

[34] M. Martín-Neira, S. Ribó, and A. J. Martín-Polegre, "Polarimetric mode of MIRAS," IEEE T Geosci Remote, vol. 40, pp. 1755-1768, Aug 2002.

[35] Reul, Nicolas ;Tenerelli, Joe ;Boutin, Jacqueline, “ Overview of the First SMOS Sea Surface Salinity products, Part I: Quality assessment for the second half of 2010”, this Special Issue, 2011.

[36] Mike Schwank, Andreas Wiesmann, Charles Werner, Christian Mätzler, Daniel Weber, Axel Murk, Ingo Völksch and UrsWegmüller, "ELBARA II, an L-Band Radiometer System for Soil 
REPLACE THIS LINE WITH YOUR PAPER IDENTIFICATION NUMBER (DOUBLE-CLICK HERE TO EDIT) <

Moisture Research", Sensors 2010, 10, 584-612; doi:10.3390/s100100584, ISSN 1424-8220, www.mdpi.com/journal/sensors

[37] J. Kainulainen, A. Colliander, J. Closa, M. Martin-Neira, R. Oliva, G. Buenadicha, P.Rubiales, A. Hakkarainen, M. Hallikainen, "Radiometric Performance of the SMOS Reference Radiometers Assessment after One Year of Operation”, this Special Issue, 2011.

[38] J.Sabater, A.Fouilloux and P. de Rosnay, " Technical implementation of SMOS data in the ECMWF integrated forecasting system”, Geosci. Remote Sens. Letters, 2011 in press.

[40] T.J. Jackson, D. LeVine, A.Y. Hsu, A. Oldak, P.J. Starks, C.T. Swift, J.D. Isham and M. Haken, "Soil moisture mapping at regional scales using microwave radiometry: The Southern Great Plains Hydrology Experiment”, IEEE Trans. Geosci. Rem. Sens., 37(5), 2136 - 2151, 1999

[41] C.J. Donlon, M. Martin, J. Stark, J. Roberts-Jones, E. Fiedler and W. Wimmer, “The Operational Sea Surface Temperature and Sea Ice Analysis (OSTIA) system”, Rem. Sens. Env., doi:10.1016/j.rse.2010.10.017, 2010

[42] ESA, "Algorithm Theoretical Basis Document (ATBD) for the SMOS level 2 Soil Moisture Processor Development Continuation Project", SO-TN-ARR-L2PP-0037, version 3.3, 16.6.2010, [available through: http://earth.esa.int/pub/ESA_DOC/SO-TN-ARR-L2PP-0037_ATBD_v3_3.pdf]

[43] ESA, "SMOS L2 OS Algorithm Theoretical Baseline Document”, SO-TN-ARG-GS-0007, version 3.3, 16.6.2010, [available through: http://earth.esa.int/pub/ESA_DOC/SO-TN-ARR-L2PP0037_ATBD_v3_3.pdf] 
REPLACE THIS LINE WITH YOUR PAPER IDENTIFICATION NUMBER (DOUBLE-CLICK HERE TO EDIT) <

[44] T. Schmugge, P. Gloersen, T. Wilheit, and F. Geiger, "Remote sensing of soil moisture with microwave radiometers,” J. Geophys. Res., vol. 79, no. 2, pp. 317-323, Jan. 1974.

[45] G. C. Thomann, "Experimental results of the remote sensing of sea surface salinity at $21-\mathrm{cm}$ wavelength," IEEE Trans. Geosci. Electron., vol. GE-14, no. 3, pp. 198-214, Jul. 1976.

[46] E. G. Njoku, J-A. Kong, "Theory for Passive Microwave Remote Sensing of Near-Surface Soil Moisture", J. Geophys. Res., Vol. 82, No. 20, July 10, 1977.

[47] M. Martin-Neira, M. Suess, J. Kainulainen, F. Martin-Porqueras, "The Flat Target Transformation", IEEE Trans. Geosci. Rem. Sens. , Vol. 46, No. 3, March 2008.

[48] Schwank, Mike ;Wigneron, Jean-Pierre ;Lopez-Baeza, Ernesto ;Völksch, Ingo ;Mätzler, Christian ;Kerr, Yann H., "L-Band radiative properties of vine vegetation at the SMOS cal/val site MELBEX III, this Special Issue, 2011.

[49] dall'Amico, Johanna T;Schlenz, Florian ;Loew, Alexander ;Mauser, Wolfram, "First Results of SMOS Soil Moisture Validation in the Upper Danube Catchment”, this Special Issue, 2011.

[50] Martin, A., "Remote sensing of sea surface salinity from CAROLS L-band radiometer in the Gulf of Biscay”, this Special Issues, 2012.

[51] Kerr, Yann H.;Waldteufel, Philippe ;Richaume, Philippe ;Wigneron, Jean-Pierre ;Ferrazzoli, Paolo ;Mahmoodi, Ali ;Al Bitar, Ahmad ;Cabot, Francois ;Gruhier, Claire ;Enache, Silvia Juglea;Leroux, Delphine ;Mialon, Arnaud ;Delwart, Steven, "The SMOS soil moisture retrieval algorithm", this Special Issue, 2011.

[52] Boutin, J. et al "First assessment of SMOS measurements over Open Ocean: part IThe Pacific Ocean”, this Special Issues, 2012. 
REPLACE THIS LINE WITH YOUR PAPER IDENTIFICATION NUMBER (DOUBLE-CLICK HERE TO EDIT) <

[53] Boutin, J. et al "First assessment of SMOS measurements over Open Ocean: part II Sea Surface Salinity", this Special Issues, 2012.

[54] Banks, Christopher J;Gommenginger, Christine P;Srokosz, MericA;Snaith, Helen M, "Validating SMOS ocean surface salinity in the Atlantic with Argo and operational ocean model data”, this Special Issue, 2011.

[55] Bircher, Simone ;Balling, Jan ;Skou, Niels ;Kerr, Yann H., "Validation of SMOS brightness temperatures during the HOBE airborne campaign, Western Denmark", this Special Issue, 2011.

[56] S. Zine, J. Boutin, J. Font, N. Reul, P. Waldteufel, C. Gabarro, J. Tenerelli, F. Petitcolin, J. L. Vergely, M. Talone, and S. Delwart, "Overview of the SMOS sea surface salinity prototype processor," IEEE T. Geosci. Remote, vol. 46, pp. 621-645, Mar 2008. 
REPLACE THIS LINE WITH YOUR PAPER IDENTIFICATION NUMBER (DOUBLE-CLICK

HERE TO EDIT) <

[57] Albergel C., Gruhier C., de Rosnay P., Muñoz-Sabater J., Hasenauer S., Isaksen L., Kerr Y., Wagner W., "Evaluation of remotely sensed and modelled soil moisture products using global groundbased in situ observations", submitted to RSE.

[58] Al Bitar, A., Leroux, D.J., Kerr, Y.H., Merlin, O., Richaume, P., Sahoo, A., \& Wood, E. (2012).

Evaluation of SMOS soil moisture products over continental US using the SCAN/SNOTEL network. this Special Issue. 


\section{REPLACE THIS LINE WITH YOUR PAPER IDENTIFICATION NUMBER (DOUBLE-CLICK HERE TO EDIT) <}

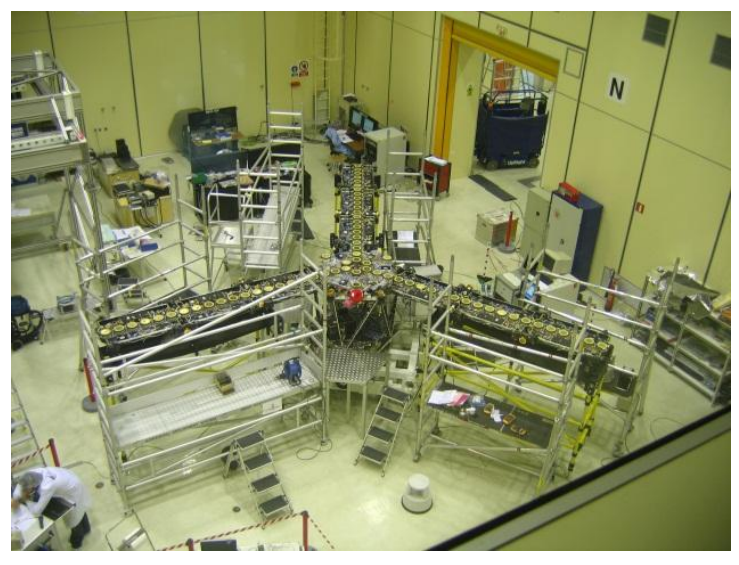

Fig. 1: SMOS in the EADS-CASA Espacio test facilities. The three-arm antenna, folded for launch, measures $8 \mathrm{~m}$ in diameter. The choice of L-Band requires novel technology to be flown in space, which has been realised with SMOS for the first time. With the antenna size being proportional to the wavelength, synthetic aperture and interferometric processing were required for a space application. 
REPLACE THIS LINE WITH YOUR PAPER IDENTIFICATION NUMBER (DOUBLE-CLICK HERE TO EDIT) <

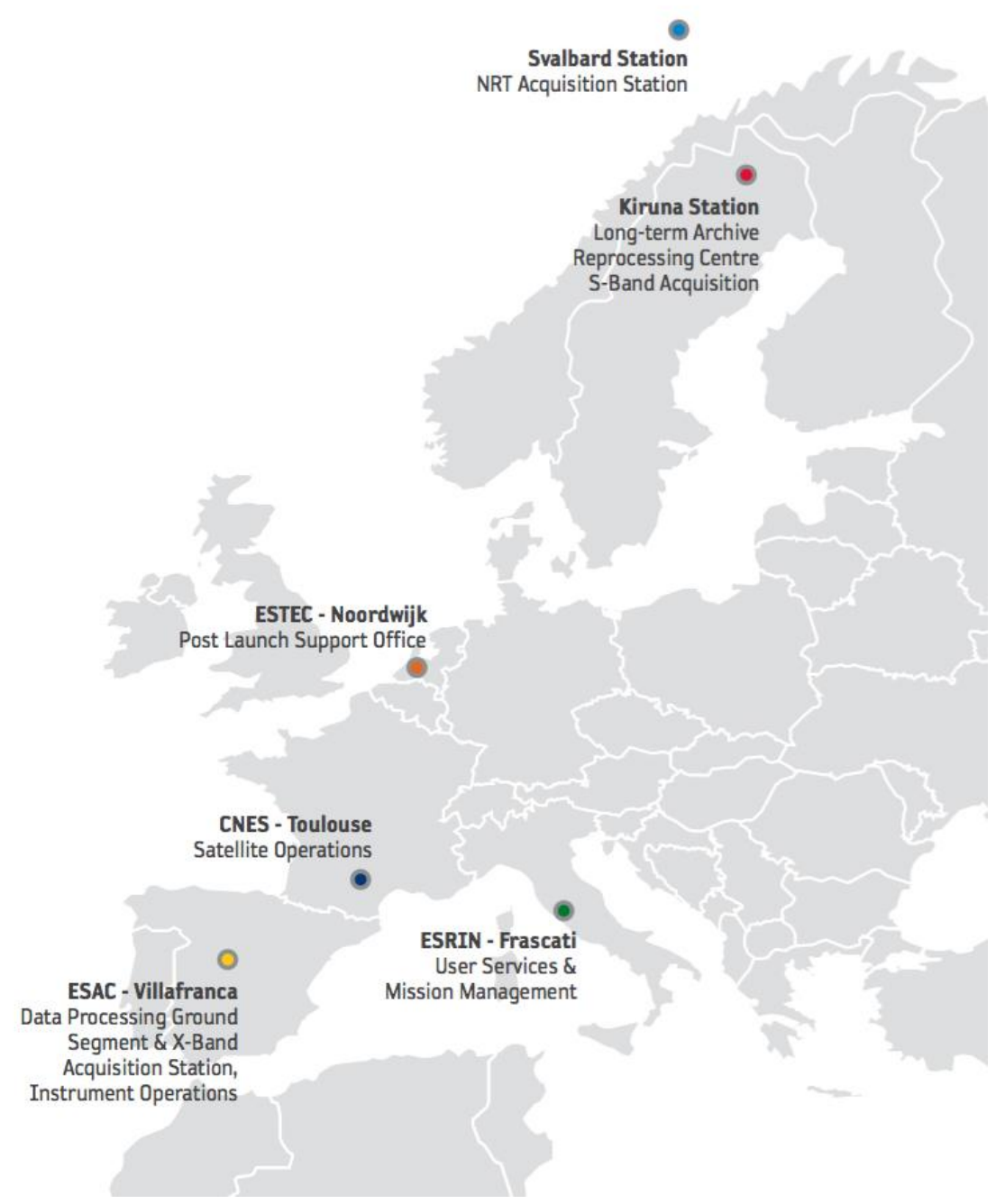

Fig.2: SMOS ground segment stations. In addition to ESA facilities various functionalities are supported by industrial contracts. 


\section{REPLACE THIS LINE WITH YOUR PAPER IDENTIFICATION NUMBER (DOUBLE-CLICK HERE TO EDIT) <}

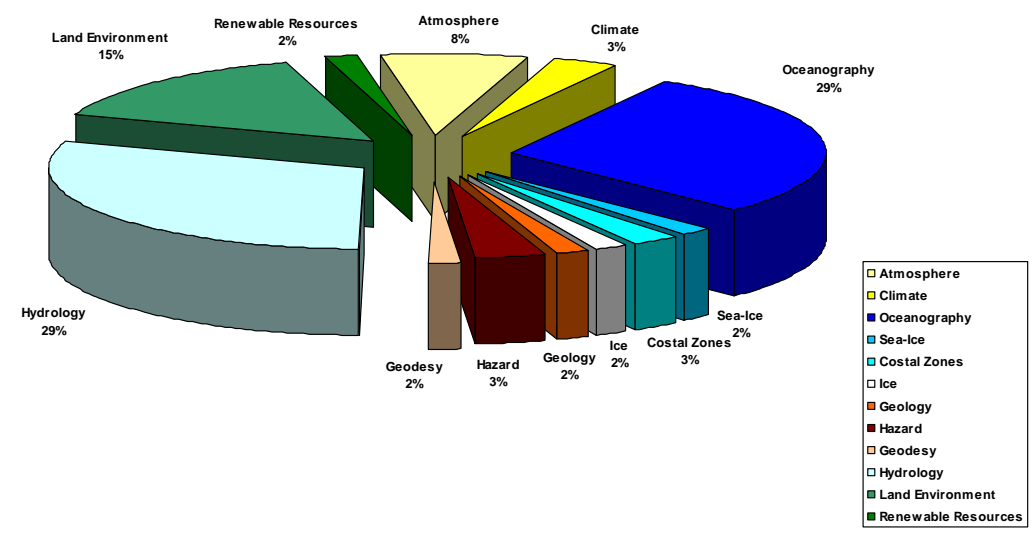

Fig.3: A total of 160 scientists and research groups have presently access to SMOS data, for both science projects as well as activities focussing on calibration and validation. Application areas range widely, with an emphasis of course on oceanographic and hydrological applications. 


\section{REPLACE THIS LINE WITH YOUR PAPER IDENTIFICATION NUMBER (DOUBLE-CLICK HERE TO EDIT) <}

\begin{tabular}{l} 
LAUNCH 2 Nov - 8 Nov \\
\hline
\end{tabular}

Fig. 4: SMOS Payload Commissioning Plan: Activities during the first six months of SMOS in-orbit, divided into four distinct sub-phases: 2.5 weeks dedicated to the Launch and Early Orbit Phase (LEOP), 3.5 weeks (extended by one week) for the Switch-On and Data Acquisition Phase (SODAP), 6.5 weeks for the MIRAS Payload Commissioning proper, and 13.5 weeks (extended by 3 weeks) for the Pseudo-Operational Phase. MIRAS was switched-on on 17 November 2009 and the acquisition of the first SMOS image take place in Week-2b, following some external as well as internal long calibrations. 


\section{REPLACE THIS LINE WITH YOUR PAPER IDENTIFICATION NUMBER (DOUBLE-CLICK HERE TO EDIT) <}
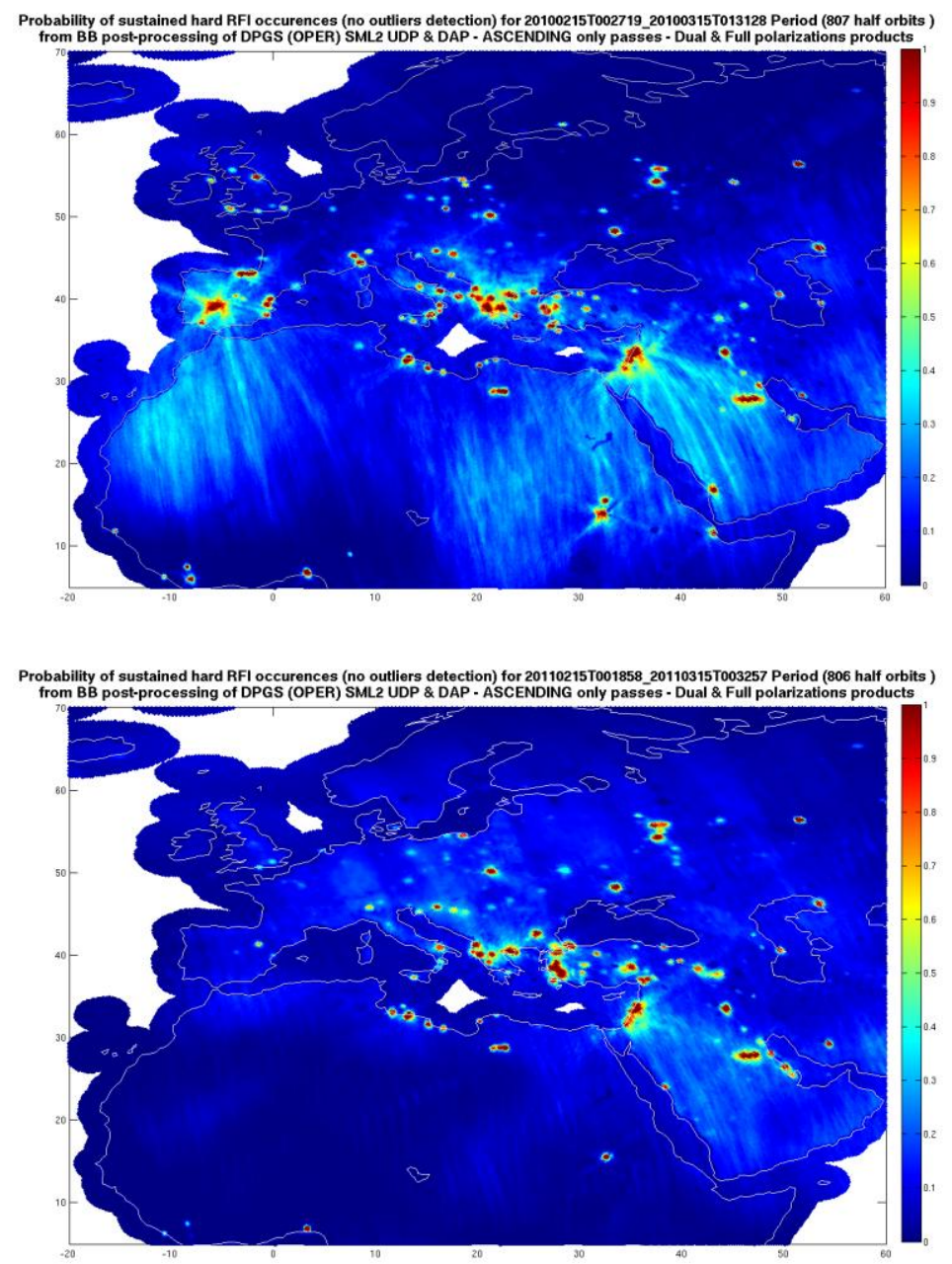

Fig. 5: Probability of RFI occurrences over Europe for ascending passes based on number of observations exceeding $340 \mathrm{~K}$ fora) 15 February to 15 March 2010 (top) and b) 15 February to 15 March 2011 (bottom), showing the effect of switching off several strong interferers (courtesy of CESBIO). Note the strong impact a single source over Spain can have on large parts of North-western Africa during ascending passes due to SMOS tilted observation mode geometry [2]. 
REPLACE THIS LINE WITH YOUR PAPER IDENTIFICATION NUMBER (DOUBLE-CLICK HERE TO EDIT) <

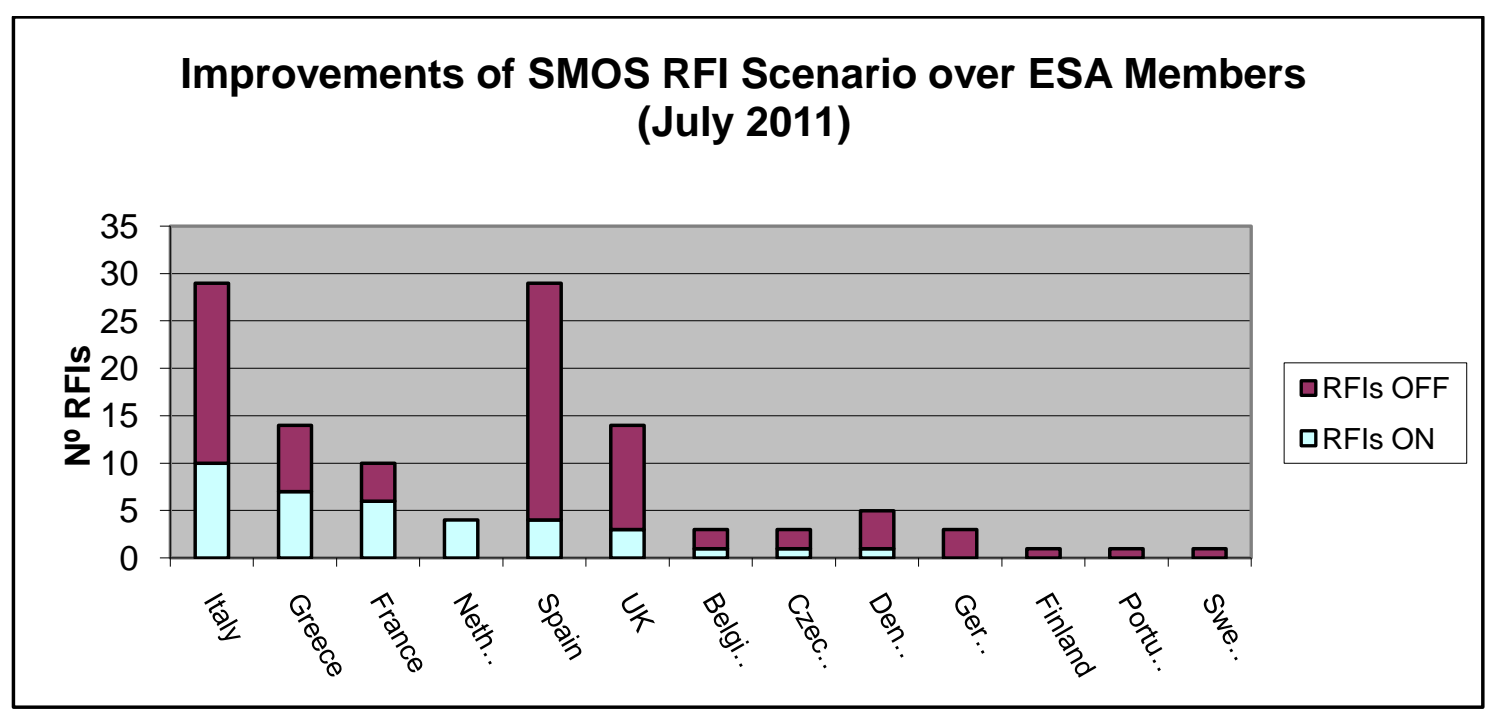

Fig. 6: Improvement of SMOS RFI scenario over Europe (status July2011). Note the large number of switched-off RFI sources. 
REPLACE THIS LINE WITH YOUR PAPER IDENTIFICATION NUMBER (DOUBLE-CLICK HERE TO EDIT) <
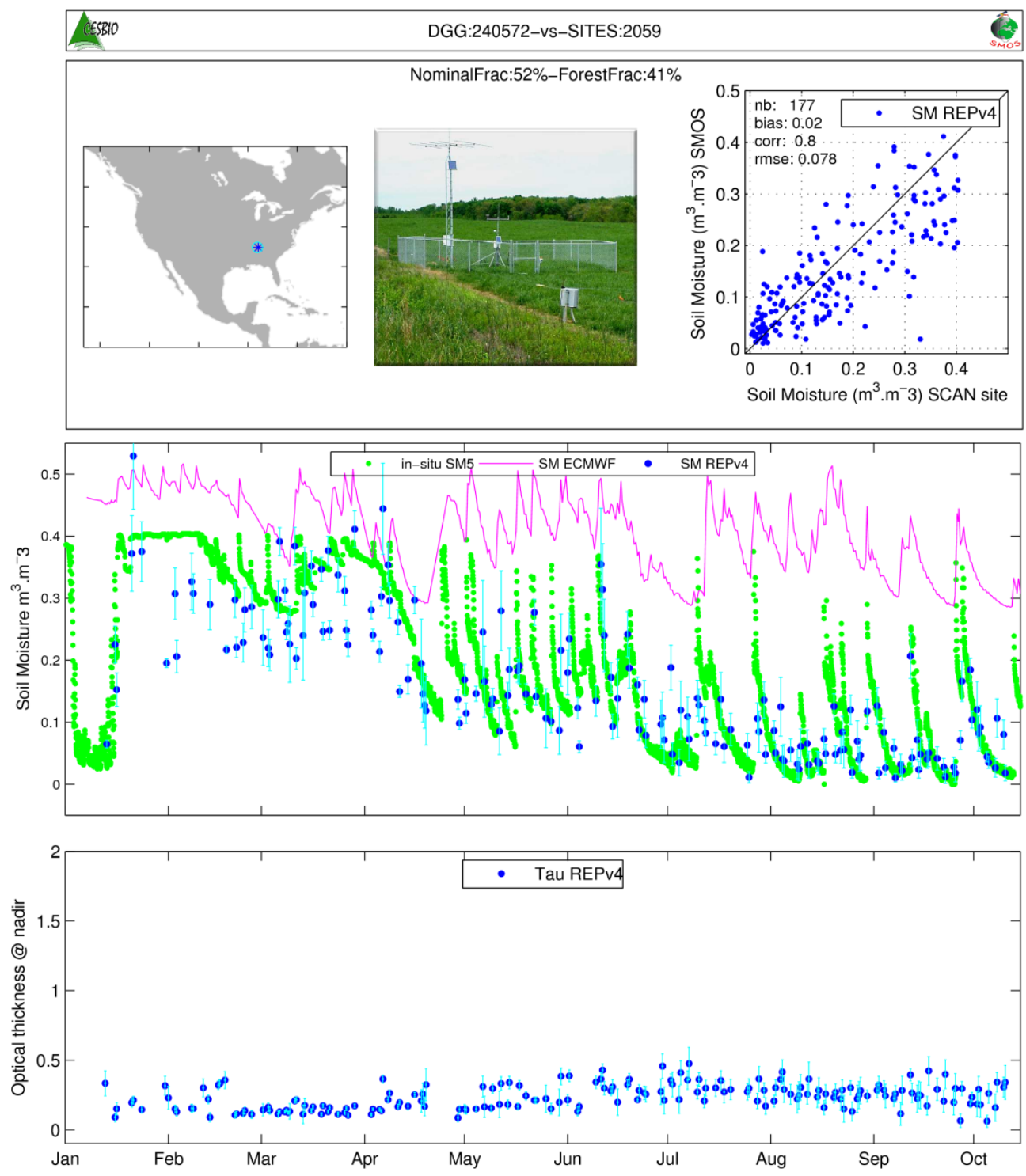

Fig. 7: Soil moisture verification using in-situ measurements from the SCAN station 2059, simulations from ECMWF's Integrated Forecast System and the SMOS Level 2 product. The bottom panel shows the SMOS optical thickness product at nadir. 


\section{REPLACE THIS LINE WITH YOUR PAPER IDENTIFICATION NUMBER (DOUBLE-CLICK HERE TO EDIT) <}
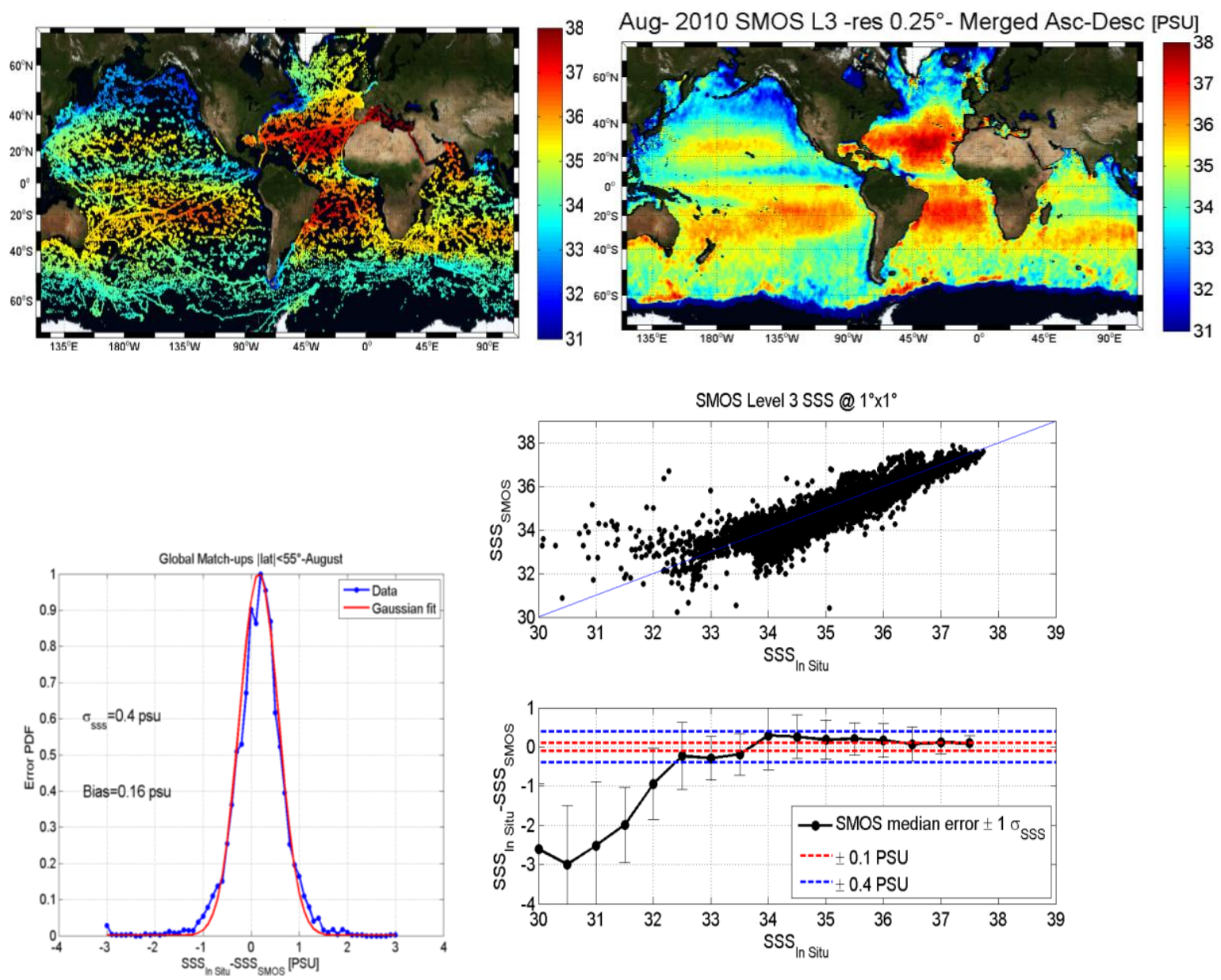

Fig. 8: Top: SMOS ocean salinity versus in-situ observations forin-situ data from July to October 2010: ensemble of in-situ data collected for validation (left) and example of SMOS Level 3 monthly averaged $1^{\circ} \times 1^{\circ}$ resolution SSS product for the month of August 2010 (right), produced at the French Centre AvalTraitement des Donnes SMOS (CATDS). Bottom: Statistics of the differences between in-situ SSS data and SMOS monthly averaged Level 3 SSS at $1^{\circ} \times 1^{\circ}$ for $\mid$ Latitude $\mid \leq 55^{\circ}$. 


\section{REPLACE THIS LINE WITH YOUR PAPER IDENTIFICATION NUMBER (DOUBLE-CLICK HERE TO EDIT) <}

Table 1 SMOS data products have been released and are available to the science users. Access to SMOS data is available a) via subscription (to receive current data immediately after acquisition on a regular basis), or b) via the ESA data product catalogue EOLI-SA (for limited amounts of data). Detailed information can be found on www.earth.esa.int/smos and www.eopi.esa.int .

\begin{tabular}{|l|l|}
\hline $\begin{array}{l}\text { SMOS data } \\
\text { product }\end{array}$ & Description \\
\hline Level 1A [10] & $\begin{array}{l}\text { Calibrated visibilities between receivers prior to applying image } \\
\text { reconstruction }\end{array}$ \\
\hline Level 1B [10] & $\begin{array}{l}\text { Output of the image reconstruction and comprising the Fourier component } \\
\text { of the brightness temperature in the antenna polarisation reference frame }\end{array}$ \\
\hline Level 1C [10] & $\begin{array}{l}\text { Multi-angular brightness temperatures at the top of the atmosphere, } \\
\text { geolocated in an equal-area grid system. Two different Level 1C products } \\
\text { are generated according to the surface type: one containing only sea and } \\
\text { the other only land pixels. Two sets of information are available: pixel- } \\
\text { wise and snapshot-wise. In addition a browse product containing } \\
\text { brightness temperatures for an incidence angle of 42.5 is available. }\end{array}$ \\
\hline $\begin{array}{l}\text { Level 2 } \\
\text { soil moisture } \\
\text { [11] }\end{array}$ & $\begin{array}{l}\text { Containing retrieved soil moisture, but also a series of ancillary data } \\
\text { derived from the processing (nadir optical thickness, surface temperature, } \\
\text { roughness parameter, dielectric constant and brightness temperature } \\
\text { retrieved at top of atmosphere and on the surface) with the corresponding } \\
\text { uncertainties }\end{array}$ \\
\hline $\begin{array}{l}\text { Level 2 } \\
\text { ocean salinity }\end{array}$ & $\begin{array}{l}\text { Containing three different ocean salinity values derived from retrieval } \\
\text { algorithms using three different models for the surface roughness } \\
\text { correction and the brightness temperature retrieved at the top of } \\
\text { atmosphere and on the sea surface, with the corresponding uncertainties. }\end{array}$ \\
\hline $\begin{array}{l}\text { Near-real time } \\
\text { product }\end{array}$ & $\begin{array}{l}\text { Level 1C data product in BUFR format, available 3 hours from sensing, } \\
\text { containing brightness temperatures at the top of the atmosphere on an } \\
\text { ISEA grid with reduced spatial resolution. An additional NRT product, the } \\
\text { so-called NRT light product, is presently under consideration adjusting the } \\
\text { spatial resolution of the NRT product to the grid size used in forecasting } \\
\text { models }\end{array}$ \\
\hline
\end{tabular}


REPLACE THIS LINE WITH YOUR PAPER IDENTIFICATION NUMBER (DOUBLE-CLICK HERE TO EDIT) <

Table 2: MIRAS calibration activities in the operations phase.

\begin{tabular}{|l|l|c|}
\hline Calibration activity & What it does & $\begin{array}{l}\text { Impact on } \\
\text { availability data }\end{array}$ \\
\hline $\begin{array}{l}\text { Flat Target Acquisition } \\
(6 \text { months })\end{array}$ & $\begin{array}{l}\text { Measurement of } \\
\text { Flat Target Response (antenna } \\
\text { errors) }\end{array}$ & $0.038 \%$ \\
\hline $\begin{array}{l}\text { Long Calibration } \\
(8 \text { weeks })\end{array}$ & $\begin{array}{l}\text { Measurement of } \\
\text { receiver and correlator errors }\end{array}$ & $0.132 \%$ \\
\hline $\begin{array}{l}\text { Cold Sky Calibration }(2 \\
\text { weeks })\end{array}$ & $\begin{array}{l}\text { Measurement of } \\
\text { Noise Injection Radiometer gain- } \\
\text { offset }\end{array}$ & $0.496 \%$ \\
\hline $\begin{array}{l}\text { Short Calibration } \\
(1 \text { week })\end{array}$ & $\begin{array}{l}\text { Measurement of } \\
\text { detector offset }\end{array}$ & $0.017 \%$ \\
\hline $\begin{array}{l}\text { Local Oscillator } \\
(10 \text { minutes })\end{array}$ & $\begin{array}{l}\text { Measurement of } \\
\text { local oscillator phase }\end{array}$ & $\mathbf{1 . 6 8 \%}$ \\
\hline & $\begin{array}{l}\text { Total of time spent on calibration } \\
\text { activities on acquired data }\end{array}$ & \\
\hline
\end{tabular}


Table 3: MIRAS instrument performance at end of commissioning phase. All parameters are within specification except for the systematic error over ocean

\begin{tabular}{|c|c|c|}
\hline System Parameter & $\begin{array}{c}\text { Specified Value } \\
\mathrm{B}=\text { boresight } \\
\text { E = Edge of swath }\end{array}$ & $\begin{array}{l}\text { Measured Value } \\
\quad \text { (in-orbit ) }\end{array}$ \\
\hline Systematic error & $\begin{array}{l}1.5 \mathrm{~K} \mathrm{rms} \mathrm{(B} \mathrm{)} \\
2.5 \mathrm{~K} \mathrm{rms} \mathrm{(E)}\end{array}$ & $\begin{array}{c}0.33 \mathrm{~K} \mathrm{rms}(\mathrm{E}, \text { sky) } \\
2.1-2.8 \mathrm{~K} \mathrm{rms} \text { (E, ocean) }\end{array}$ \\
\hline $\begin{array}{l}\text { Level } 1 \text { soil moisture } \\
\text { Radiometric Sensitivity }(1.2 \mathrm{~s}-220 \mathrm{~K})\end{array}$ & $\begin{array}{l}3.5 \mathrm{~K} \mathrm{rms}(\mathrm{B}) \\
5.8 \mathrm{~K} \mathrm{rms}(\mathrm{E})\end{array}$ & $\begin{array}{l}2.5 \mathrm{~K} \mathrm{rms} \mathrm{(B,} \mathrm{Antarctica)} \\
4.0 \mathrm{~K} \mathrm{rms} \mathrm{(E,} \mathrm{Antarctica)}\end{array}$ \\
\hline $\begin{array}{l}\text { Level } 1 \text { ocean salinity } \\
\text { Radiometric Sensitivity }(1.2 \mathrm{~s}-150 \mathrm{~K})\end{array}$ & 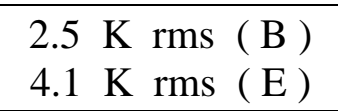 & $\begin{array}{l}2.0 \mathrm{Krms}(\mathrm{B}, \text { ocean }) \\
2.5 \mathrm{Krms} \text { (E, ocean) }\end{array}$ \\
\hline $\begin{array}{l}\text { Short Term Stability } \\
(1.2 \mathrm{~s})\end{array}$ & $\begin{array}{l}4.1 \mathrm{~K} \text { rms }(\mathrm{E}) \\
\text { (during } 10 \text { days) }\end{array}$ & $\begin{array}{c}3.5-3.8 \text { Krms (E, ocean) } \\
\text { (over } 2 \text { weeks) }\end{array}$ \\
\hline Long Term Stability & $\begin{array}{l}0.03 \mathrm{~K} / 2 \text { months } \\
0.18 \mathrm{~K} / \text { year }\end{array}$ & $\begin{array}{c}0.14 \mathrm{~K} / \text { year (sky) } \\
0.25 \mathrm{~K} / \text { year (ocean) } \\
0.24 \mathrm{~K} / \text { year (Antarctica) }\end{array}$ \\
\hline Pointing & $400 \mathrm{~m}$ & $\begin{array}{l}221 \mathrm{~m} \text { (ascending orbit) } \\
388 \mathrm{~m} \text { (descending orbit) }\end{array}$ \\
\hline
\end{tabular}

